\title{
Assessing the effects of COVID-19-related risk on online shopping behavior
}

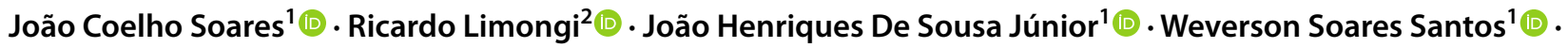 \\ Michele Raasch ${ }^{1}\left[\right.$. Lenoir Hoeckesfeld ${ }^{3}$ (D)
}

Revised: 5 September 2021 / Accepted: 11 January 2022 / Published online: 7 February 2022

(c) The Author(s), under exclusive licence to Springer Nature Limited 2022

\begin{abstract}
In times of pandemic and social distancing, the risks tied to leaving home to make purchases can cause consumers to seek online means to perform such activities. In this sense, the study aims to analyze the influence of COVID-19 on online shopping behavior. For this, we apply a survey with 1052 Brazilian online consumers, with data analyzed via PLS-SEM. As main results, we observed that the perceived risk of being infected with COVID-19 when buying in person positively impacted the perceived usefulness and ease of purchase. However, it had no statistical influence on online shopping intent; perceived usefulness is positively related to online purchase intent; and perceived ease of investment has a significant positive association with perceived usefulness and online purchase intent. Online purchase intent positively affects online shopping. The research contributes to the literature by offering empirical results using TAM and COVID-19 as an external model variable.
\end{abstract}

Keywords Online purchase $\cdot$ Consumer behavior $\cdot$ COVID-19 perceived risk $\cdot$ Perceived usefulness $\cdot$ Perceived ease of purchase

Ricardo Limongi

ricardolimongi@ufg.br

João Coelho Soares

joaocsoares88@gmail.com

João Henriques De Sousa Júnior

sousajunioreu@hotmail.com

Weverson Soares Santos

weverson_ss@hotmail.com

Michele Raasch

micheleraasch@hotmail.com

Lenoir Hoeckesfeld

leno.adm@gmail.com

1 Federal University of Santa Catarina, Campus Universitário - Trindade, Florianópolis, Santa Catarina CEP 88040-900, Brazil

2 Federal University of Goias, Av. Esperança s/n, Campus Samambaia- Prédio da Reitoria, Goiânia, GO CEP 74690-900, Brazil

3 Federal Institute of Mato Grosso, Rodovia MT 208, s/n - Lote 143-A, Loteamento Aquarela - Hamoa, Caixa Postal 148, Alta Floresta, MT CEP 78580-000, Brazil

\section{Introduction}

The growing number of internet users worldwide emphasizes its importance in the various aspects of society, transforming it into a relevant communication tool and a support platform for creating new businesses. Currently, 4.57 billion people are using the internet worldwide, representing an annual increase of more than 7\% compared to previous years (Kemp 2020).

Furthermore, the potential of the online environment for companies and the insertion of organizations in this environment have become a constant practice that seeks to differentiate themselves in the market (Kietzmann et al. 2011). However, by defining the allocation of resources and investment in developing and adopting information technologies, organizations face risky investment in decisions that can affect their competitive position (Davis and Venkatesh 1996; Sun 2017). These decisions will certainly affect the company and its audience. So, it is salutary to understand that consumer purchasing decisions can be affected by several factors, such as, for example, in public health emergencies (Yan et al. 2020; Wang et al. 2020).

The COVID-19 pandemic affected the daily life of all (Kim 2020) and brought direct and indirect consequences 
not only in the field of public health but also in public safety, education, logistics, and economics, for example. It is perceived that, and all over the world, people have used more time in digital activity because of the restrictive measures imposed as ways of containing the exponential curve of contamination of COVID-19, especially in countries that have suffered from lockdown and decreased social interaction (Kemp 2020).

Although online purchases have certain risks, such as privacy issues and product delivery, their benefits eventually outperform and lead people to make this type of purchase (Chiu et al. 2014; Sheth 2020). The pandemic has accelerated the pace of growth in online sales, causing companies in and across diverse segments to invest in making digital selling more effective and accessible (Kim 2020). Thus, as a large portion of the population has found restrictions on activities and remained isolated or distanced within their homes, this public ended up being exposed to a more significant advertising appeal. Thus, it is crucial to understand this trend in the search for online commerce motivated by the blocking of physical stores and restrictions on human contacts and social interaction (Addo et al. 2020).

To better attract consumer attention in the online environment, companies must know the attitudes and behaviors of their consumers to online shopping and their background (Chiu et al. 2005). Latin America is an emerging market with a growth in the number of people buying online (Ventre and Kolbe 2020). As data from the first quarter of 2020 presented in the Kantar report (2020), in Brazil, e-commerce had already attracted more than 1.2 million new homes. It reached a frequency three times higher in 2020, indicating that the market is transitioning to e-commerce. In the second quarter of the same year, according to Kemp's study (2020), half of those surveyed mentioned buying online for longer, reaffirming the exponential growth of this consumer profile. The rise of online shopping offers new opportunities for businesses during and after COVID-19 (Kim 2020).

Kim (2020) pointed out recently, the pandemic was an accelerator of structural change in consumption and digital transformation in the market, to the point that companies that have not made such a transition to digital have already drastically reduced access to their customers and thus are less likely to survive the pandemic.

Despite the exponential growth in the number of infected worldwide throughout the first half, a slowdown in the rate of contagions in some places led to the relaxation of specific restrictive measures, causing people to return to leave home to resume some of their activities (WHO 2020). However, the return to work and exposure to the risk of COVID-19 infection may contribute to the ad's resumption of mobility (Yan et al. 2020). Given this risk exposure, studies such as Kim (2020), Yan et al. (2020), and Sheth (2020) indicate that the pandemic could leave lasting impacts on consumer culture, may have transformed the structure of the market for the post-pandemic period, influenced consumer purchasing decisions, and even created new real and lasting buying habits and behaviors.

In this sense, the pandemic's impacts and reflexes on consumer behavior and market dynamics show the relevance and need for academic deepening of the theme (Kim 2020). It is imperative to understand the trend and impacts of the COVID-19 pandemic on consumer buying behavior (Addo et al. 2020) and how to expand the understanding of the effect of COVID-19 on consumers and consumer crops (Kim 2020). There is a need for more studies on the effect of risk perception toward epidemics on consumer behavior and decision making (Shim et al. 2021).

The concern of researchers in understanding the consumer behavior in the face of changes imposed by the pandemic scenario, hitherto unknown, within the time limit of one year of pandemic, can be seen. A review of research related to consumer behavior in the COVID-19 pandemic is presented by Silva et al. (2021). The authors identified a focus on research on changes in consumption habits and behaviors in the face of social isolation, focusing on the food context, with most of the studies occurring in the United States and China (Silva et al. 2021). Among the research identified on consumer behavior in the context of the COVID-19 pandemic, Troise et al. (2021) used the combination of TAM and TPM to understand the adoption of online food delivery behavior among Italians. Their results point to greater perceived usefulness with deliveries due to their convenience. The perceived risks of COVID-19 affect behavioral intentions negatively and showed a significant relationship with the perception of ease of use for online food delivery (Troise et al. 2021). The study by Kim et al. (2021) analyzes the perceived risk of contamination of North American hotel guests and uses technology (robots) to reduce this risk. Through four experiments, they identified that contrary to what occurred before COVID-19, consumers had positive attitudes toward hotels that used this technology.

These results show that there is still room for empirical research exploring the relationship between the pandemic and consumer behavior in different contexts, like in Brazilian e-commerce. Thus, the present study aims to analyze the influence of the COVID-19 pandemic on online shopping behavior through a proposed model and data collected from Brazilian online consumers.

In this context, it is salutary to highlight that this study contributed positively to the advancement of studies investigating online shopping behavior during the pandemic, identifying that the pandemic scenario influences online purchasing behavior and that one of the possible causes for the growth of online shopping is due to the higher exposure 
of people to the internet, enhancing their perception of usefulness and ease of purchase-related to online shopping.

\section{Literature review}

The technology acceptance model (TAM) investigates the impacts of usefulness and perceived ease of use in attitudes toward internet use, behavioral intentions, and actual use (Law et al. 2016). The model was designed to understand the causal chain that links external variables to their acceptance by the user and their actual use, and use proved to be among the most effective models to predict user acceptance and use behavior (Davis and Venkatesh 1996). However, changes in TAM have already been made since the model was created for a general explanation of the determinants of acceptance of computer technology and not for specific topics, such as behavioral intentions of online shopping (Chiu et al. 2005). The original TAM or a modified/extended version has already been used to analyze online purchase behavior in different contexts.

Fayad and Paper (2015) point out the need to study behavioral expectations, in addition to behavioral intentions, when predicting purchasing behavior using the TAM; the research carried out by the authors sought to support TAM's robustness in consumer research. The TAM model is one of the most used models in research that aims to identify the perceived usefulness and simplicity of use in consumption decisions (Fedorko et al. 2018).

In this sense, TAM can be applied in different contexts of online consumer behavior (Koufaris 2002; Chi 2018). TAM has been previously used in the literature to understand the online shopping process, such as the research by Tong (2010) and Ishfaq and Mengxing (2021). In Tong (2010), the TAM model was used to understand the online shopping behavior of consumers in the USA and China, to examine the main factors influencing the purchase decision of online shoppers in the retail sector. Recently, Ishfaq and Mengxing (2021) used the TAM model to predict users' behavioral intention regarding the purchase of services during the COVID-19 pandemic.

Thus, the research model and hypotheses were elaborated based on the literature on the subject.

\section{Perceived Risk of COVID-19}

Consumer purchasing decisions and behaviors are complex processes affected by internal and external factors (Chu 2018). In TAM, the external variables are theorized to influence the behavioral intention of use indirectly and, later, its use through its influence on the usefulness and perceived ease of use (Davis and Venkatesh 1996). External factors act through external contextual events/factors, such as unexpected public health emergencies (Yan et al. 2020), such as the perceived pandemic-related risk of COVID-19.

Perceived risk can be understood as the subjective assessment of the probability of encountering a threat and the consequences and dangers of this threat (Zhang et al. 2018; Yan et al. 2020). In the present study, this dimension seeks to identify the perceived risk of COVID-19, defined through a person's subjective evaluation about the probability and severity of becoming infected by COVID-19 while making purchases in person in commercial establishments. Perceived risk can influence utilitarian value in purchase intention (Chiu et al. 2014). Most consumers are concerned about the situation of the COVID-19 pandemic (Nguyen et al. 2020); consequently, this concern affects their way of consuming (Sheth 2020).

The perceived risks of COVID-19 can negatively influence the behavioral intentions of consumers (Troise et al. 2021) and lead to changes in people's behavior and consumption patterns (Brewer and Sebby 2021). In a pandemic context, the perceived risk and the threat of contagion influenced consumer behavior changes, emerging a greater preference for the use of technologies to socially distance themselves from humans (Kim et al. 2021).

For many consumers, buying in face-to-face stores can pose a health risk, encouraging them to look for online alternatives to their purchases. Since buying in physical stores and buying online are two different activities (Chiu et al. 2005), the pandemic influences the transition in the consumer culture from face-to-face to online shopping (Kim 2020).

Previous research has indicated that perceived risk determines purchase intention (Chiu et al. 2014; Zhang et al. 2018; Yan et al. 2020). The study of Yan et al. (2020) analyzes the changes in intentions of buying cars before and after the outbreak of COVID-19 in China. The results revealed that the outbreak of this epidemic strongly influenced the intentions of buying cars of some consumers. In addition, they also observed that the probability of being infected by the virus during a trip motivates consumers to adopt various protective behaviors (Yan et al. 2020).

Nguyen et al. (2020) revealed that the COVID-19 pandemic has a positive and significant impact on consumers' intention to buy books online, i.e., consumers have adopted new online consumption habits, such as books, during the pandemic. This study also pointed out that consumers have a strong concern about the health risks associated with going to these stores in person, choosing to buy in e-commerce. Recently, the COVID-19 risk perception has been positively associated with consumers' perception of convenience and purchase intentions when ordering food online (Brewer and Sebby 2021).

Given what has been presented in the literature and believing that the perceived risk of making purchases in 
person during the pandemic favors the search for online shopping, the first three research hypotheses are as follows:

H1 The perceived risk of being infected by COVID-19 when buying in person positively affects the perceived usefulness.

H2 The perceived risk of being infected by COVID-19 when buying in person positively affects the perceived ease of purchase.

H3 The perceived risk of being infected by COVID-19 when buying in person positively affects online purchase intention.

\section{Perceived usefulness}

As TAM suggests, perceived usefulness determines the intention to adopt a specific technology (Fortes and Rita 2016). The perceived usefulness for online shopping can be defined as the subjective probability of the potential consumer that the internet will provide their purchases more efficiently than face-to-face purchases (Koufaris 2002; Chiu et al. 2014; Law et al. 2016). In the present study, perceived use is understood as the individual's perception of the degree to which internet use will improve their purchasing performance (e.g., convenience, agility, timesaving).

The literature suggests that perceived usefulness is positively related to purchasing intention (Law et al. 2016). E-commerce is seen as more economical and convenient than face-to-face purchases (Ventre and Kolbe 2020). When the consumer believes that the use and specific site is helpful to carry out their purchases, they will probably have a better attitude toward the site and will return to use it (Koufaris 2002; Moslehpour et al. 2018). E-commerce generally offers a wide variety of products, increasing the likelihood of consumers finding the desired product than offline purchases, providing a more effective shopping experience (Chiu et al. 2014). When users understand the internet as a helpful tool, this increases its frequency, duration, and use, changing consumers' purchasing platform (Isaac et al. 2017).

The perceived usefulness has a positive effect on internet use (Isaac et al. 2017), and previous studies have already observed significant and positive relationships between perceived usefulness and online purchase intention (Chiu et al. 2005; Law et al. 2016; Moslehpour et al. 2018; Sukno and Riquelme 2019) and attitudes toward e-shopping (Çelik and Yilmaz 2011). Moslehpour et al. (2018) identified that Taiwanese online consumers who perceive technology as a valuable tool for shopping online tend to make more online purchases. Sukno and Riquelme (2019) found similar results in C2C e-commerce in Chile. Ventre and Kolbe (2020) identify the perceived usefulness of online reviews as the essential factor in online shopping intention for Mexican consumers aged 18 to 50 years old who use e-commerce. In this sense, based on the existing literature and research objectives, the hypothesis four of the study is as follows:

H4 Perceived usefulness positively affects online purchase intention.

\section{Perceived ease of purchase}

In TAM, the dimension that corresponds to the degree to which a person believes that using a specific system would be effort-free is called "perceived ease of use" (Davis and Venkatesh 1996). The literature suggests that ease of use positively influences the attitude and intention to use a given technology (Law et al. 2016). The literature also points out that the perceived ease of use positively affects the perceived usefulness, stating that the more accessible the user perceives a specific technology (e.g., internet), the more valuable, for the user, the technology will be perceived (Isaac et al. 2017).

However, as in other studies (Chiu et al. 2005; Law et al. 2016), this research changes the focus of the dimension because this is something more general to technology, directing its scope and denomination of what format the ease of purchase is perceived. Thus, the perceived ease of purchase is conceptualized as the individual's expectation that online purchase will require less effort than a face-to-face purchase (Koufaris 2002; Law et al. 2016). When focusing on consumer efforts about online shopping issues, the dimension can be seen as an evolution of the old construct (perceived ease of use) because the ease of use of the internet has become increasingly common among its users. In contrast, the ease of online shopping is not yet familiar to everyone (Chiu et al. 2005).

According to Çelik and Yilmaz (2011), the internet and e-commerce rapidly spread new and effective ways to shop online, such as smartphone apps (Wang et al. 2020). The user perceives the more ease of use to some technology, the greater the perception of the usefulness of this technology and predisposes to use it more often (Sukno and Riquelme 2019). The perceived ease of use is also relevant to the online shopping experience, strongly associated with the purchase intention (Moslehpour et al. 2018). In a study related to the purchase intention of a particular brand of coffee, it was possible to observe that the ease of App (software application) use positively affects the purchase intention in coffee services (Shim et al. 2021).

Previous research also suggested a positive relationship between perceived ease of use and perceived usefulness (e.g., Çelik and Yilmaz 2011; Kim 2012; Manis and Choi 2019; Sukno and Riquelme 2019). However, the empirical results may differ, suggesting that the effect of perceived ease of use on perceived usefulness and purchase intention may be different according to the context and technology 
researched (Isaac et al. 2017). For instance, the perceived ease of use positively influenced the perceived usefulness but did not significantly affect the purchase intention in the Chilean context (Sukno and Riquelme 2019). The perceived ease of use did not statistically affect perceived usefulness in a study related to YouTube for procedural learning (Lee and Lehto 2013).

Specifically related to the perceived ease of purchase dimension, previous literature showed that this dimension positively influences online purchase intentions when analyzed in the context of customers of Taiwan's largest internet service provider (ISP) (Chiu et al. 2005) and among adults aged from 31 to 60 years old in Hong Kong (Law et al. 2016). Thus, the fifth and sixth hypotheses of the study are as follows:

H5 Perceived ease of purchase positively affects perceived usefulness.

H6 Perceived ease of purchase positively affects online purchase intention.

\section{Online purchase intention}

The intention is the cognitive representation of a person's readiness to perform a given behavior, and intention is the best predictor of actual behavior (Wee et al. 2014). Online purchase intention can be defined as measuring a consumer's intention to perform a specific internet buying behavior (Chiu et al. 2005). As the literature suggests (Wang and Herrando 2019), the present study investigates consumers' actual buying behavior rather than just examining the purchase intention.

Customer loyalty or repeated consumer buying is critical to the survival and success of any business (Chiu et al. 2014). Consumers spend their time in e-commerce looking for information and evaluating product options so that they progressively build an intention to buy that could become an actual purchase (Wang and Herrando 2019). Individual attitudes affect users' behavioral intentions, which influence their actual behavior.

A recent survey published by We Are Social showed a trend of behavior change regarding online shopping (Kemp 2020). Data showed that $47 \%$ of internet users said they spent more time shopping online during the pandemic. Some sectors and product categories have seen a significant increase in sales. There was a $251 \%$ increase in visits to supermarket websites, while purchases increased by $76 \%$. Sheth's (2020) survey also pointed out a significant increase in food retail and bar online shopping. Previous research has also observed that consumer buying intention is positively associated with their actual buying behavior (Çelik and Yilmaz 2011; Wee et al. 2014; Wang and Herrando 2019). There's a link between the intention to use e-commerce and online purchases (Çelik and Yilmaz 2011). Thus, it was decided to formulate the seventh and final hypothesis of the present study:

H7 The intention of online shopping positively affects online shopping behavior.

Thus, Fig. 1 presents the study research model and summarizes the five dimensions and the seven established research hypotheses.

Table 1 summarizes some relevant insights and findings of the literature reviewed.

\section{Method}

We apply a quantitative, exploratory approach, with data collected via an online survey and analyzed through descriptive statistics and the partial least squares structural equation modeling (PLS-SEM) technique. For the survey, a questionnaire was used for data collection. The dimensions and items of the questionnaire were identified from existing literature, translated (reverse translation), analyzed, and adapted, aiming for compatibility with the current research theme and

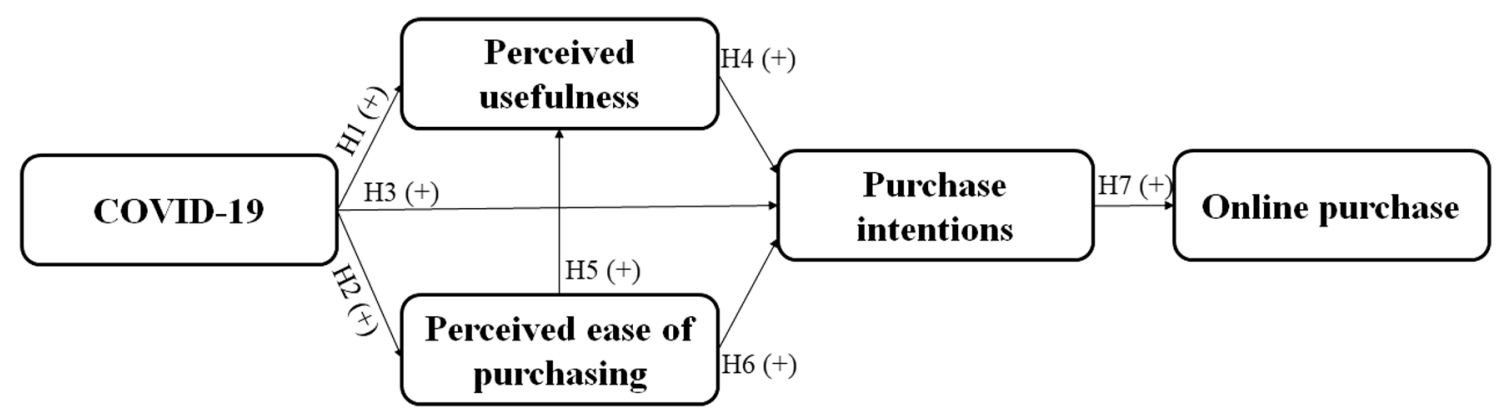

Fig. 1 Study framework 
Table 1 Key insights in the literature reviewed

\begin{tabular}{|c|c|}
\hline Topic & Key insights/results \\
\hline Perceived risk of COVID-19 & $\begin{array}{l}\text { The perceived risks of COVID-19 affect behavioral intentions negatively (Troise et al. 2021) } \\
\text { The perceived risks of COVID-19 are positively associated with consumers' perception of convenience and } \\
\text { purchase intentions when ordering food online (Brewer and Sebby 2021) }\end{array}$ \\
\hline Perceived usefulness & $\begin{array}{l}\text { According to TAM, perceived usefulness can be a determining factor in a consumer's intention to adopt a par- } \\
\text { ticular technology (Fortes and Rita 2016) } \\
\text { Perceived usefulness positively affects attitudes toward e-shopping (Çelik and Yilmaz 2011) } \\
\text { Perceived usefulness positively affects online purchase intention (Chiu et al. 2005; Law et al. 2016; Moslehpour } \\
\text { et al. 2018; Sukno and Riquelme, 2019) }\end{array}$ \\
\hline Perceived ease of use/purchase & $\begin{array}{l}\text { The influence of perceived ease of use on perceived usefulness may be differ according to the context and tech- } \\
\text { nology (Isaac et al. 2017) } \\
\text { Perceived ease of use significantly affects perceived usefulness (Çelik and Yilmaz 2011; Kim 2012; Manis and } \\
\text { Choi 2019; Sukno and Riquelme, 2019) and online purchase intention (Moslehpour et al. 2018) } \\
\text { Perceived ease of purchase can positively affect online purchase intention (Chiu et al. 2005; Law et al. 2016) }\end{array}$ \\
\hline
\end{tabular}

local context. Table 2 presents the five dimensions surveyed, descriptions, and primary references.

The items related to dimension perceived risk of COVID19 are based on Zhang et al. (2018) and Yan et al. (2020), and the three dimensions related to the technology acceptance model (perceived usefulness, perceived ease of purchase, and online purchase intention) were adapted from Chiu et al. (2005), Çelik and Yilmaz (2011), and Law et al. (2016). The items relating to "online purchase" are based on Çelik and Yilmaz (2011).

After adapting the items to the research context, we sought to validate the instrument before collecting the data. Content validity and face validity were performed to reduce possible errors resulting from the use of irrelevant or insufficient measures and improve the understanding of the instrument. At first, a group of experts (composed of researchers and marketing professionals) reviewed the initial questionnaire and forwarded feedback on the ease of understanding of the instrument, the adequacy of the terms used, and the consistency of the sequence of items. The order of the items was changed, and the translation of the terms used was adapted for the Portuguese. Subsequently, the instrument underwent a pre-test process with the target audience. 12 Brazilian online consumers (who did not participate in the final sample) answered the questionnaire in this situation. It provided feedback on semantic adequacy (ease of understanding of instructions, items, and response options) and the survey format (online tool used, colors, size, and font type). The feedback led to some specific changes in text and terms used in certain items, aiming at a better understanding by the respondents.

The final instrument used to collect the survey data has 30 items, starting with a request for authorization of the respondent to participate in the study, five questions related to identifying the respondents' profile and socio-demographic data, and 24 items related to the five dimensions present in the research model. The complete instrument and its articles are available in the Online Appendix.

The non-probabilistic convenience sampling technique selected the sample. The data collection period (between June 15 and 21,2020) coincides with the change of season: from autumn to winter on June 20th, the first winter during the pandemic in Brazil. During data collection, the country had registered 1 million cases related to COVID-19. Data were collected with an online form (Google Forms), whose link was made available through email (to groups of students, professors, researchers, and university workers) and disclosure on digital social media (Facebook and

Table 2 Dimensions of the framework, description, and main authors

\begin{tabular}{|c|c|c|c|}
\hline Dimension & Acronym & Description & Primary references \\
\hline Perceived risk of COVID-19 & $\mathrm{COV}$ & $\begin{array}{l}\text { A person's subjective assessment of the probability and severity } \\
\text { of becoming infected by COVID-19 while shopping in person }\end{array}$ & Zhang et al. (2018), Yan et al. (2020) \\
\hline Perceived usefulness & PU & $\begin{array}{l}\text { The individual's perception of the degree to which internet use } \\
\text { will facilitate and improve their purchasing performance }\end{array}$ & $\begin{array}{l}\text { Chiu et al. (2005), Çelik and Yilmaz } \\
\text { (2011), Law et al. (2016) }\end{array}$ \\
\hline Perceived ease of purchase & EOU & $\begin{array}{l}\text { The individual's expectation that online purchase will require } \\
\text { less effort than a face-to-face purchase }\end{array}$ & \\
\hline Online purchase intention & PI & $\begin{array}{l}\text { The individual's intention to perform a specific online buying } \\
\text { behavior }\end{array}$ & \\
\hline Online purchase & OP & The act or behavior of shopping online & Çelik and Yilmaz (2011) \\
\hline
\end{tabular}


WhatsApp). The sample was selected due to the greater ease of online access for individuals, given the mobility restrictions present at data collection. Such people are part of the target audience for being present online and purchasing through this channel.

The sample selection was carried out with no age limit for the respondents, given that previous studies based on TAM were carried out with different age groups, such as with people aged from 31 to 60 years old (Law et al. 2016), from 16 to 74 years old (Fortes and Rita 2016), from 16 to 45 years old (Moslehpour et al. 2018), below 30 years old (Wei et al. 2018), or with average age around 27 years old (Sukno and Riquelme 2019). Based on these studies, it's suggested that TAM can be used in research involving purchasing behavior with consumers of all ages. At the end of that data collection period, a total number of 1053 questionnaires were answered.

The initial analysis of the data was verified by verifying the completion and validation of the questionnaires received. Of the total of 1053 questionnaires received, only one person indicated, in the first question, not wanting to participate in the survey and therefore excluded from the final sample, which results in 1052 valid and duly completed questionnaires. It is observed that this number of respondents is higher than the minimum estimate of the sample size, recommended by the "ten times rule," which consists of a method of estimating minimum sample size widely used in studies with PLS-SEM (Hair et al. 2011; 2012).

Following the data analysis, we used the PLS-SEM (partial least squares structural equation modeling) technique through the SmartPLS software, version 3, to test the proposed model and the seven hypotheses. This technique has been chosen for being indicated for research in consumer behavior (Hair Jr et al. 2011) and has already been used by several studies (e.g., Chiu et al. 2014; Law et al. 2016; Arora and Sahney 2018; Wang and Herrando 2019; Ventre and Kolbe 2020).

\section{Analysis of results}

\section{Sample profile}

This section presents the profile of the study participants. Table 3 shows the main characteristics of the respondents' profiles.

Among the 1,052 respondents, it is noteworthy that the majority $(74.8 \%)$ declared themselves as female, while $25.2 \%$ as male, $0.4 \%$ preferred not to answer, and $0.1 \%$ were classified with "Other." Concerning the age group, $35.6 \%$ of participants were between 25 and 31 years old, $29.6 \%$ were up to 24 years old , $17.3 \%$ were between 32 and 38 years old , $9.9 \%$ were over 45 years old , $7.1 \%$ were between 39 and
Table 3 Respondents' profile

\begin{tabular}{|c|c|c|}
\hline \multicolumn{3}{|l|}{ Gender } \\
\hline Female & 782 & $74.33 \%$ \\
\hline Male & 265 & $25.19 \%$ \\
\hline Other & 1 & $0.10 \%$ \\
\hline I'd rather not answer & 4 & $0.38 \%$ \\
\hline \multicolumn{3}{|l|}{ Age } \\
\hline Up to 24 years old & 311 & $29.56 \%$ \\
\hline Between 25 and 31 years old & 374 & $35.55 \%$ \\
\hline Between 32 and 38 years old & 182 & $17.30 \%$ \\
\hline Between 39 and 45 years old & 75 & $7.13 \%$ \\
\hline Over 45 years old & 104 & $9.89 \%$ \\
\hline I'd rather not answer & 6 & $0.57 \%$ \\
\hline \multicolumn{3}{|l|}{ Marital status } \\
\hline Single & 657 & $62.45 \%$ \\
\hline Married or stable union & 351 & $33.37 \%$ \\
\hline Divorced or widowed & 40 & $3.80 \%$ \\
\hline I'd rather not answer & 4 & $0.38 \%$ \\
\hline \multicolumn{3}{|l|}{ Education } \\
\hline Elementary or high school & 215 & $20.44 \%$ \\
\hline Graduate & 302 & $28.71 \%$ \\
\hline Postgraduate (MBA and Ph.D.) & 531 & $50.48 \%$ \\
\hline I'd rather not answer & 4 & $0.38 \%$ \\
\hline \multicolumn{3}{|l|}{ Income } \\
\hline Up to 2 minimum wages & 235 & $22.34 \%$ \\
\hline From 2 to 4 minimum wages & 295 & $28.04 \%$ \\
\hline From 4 to 6 minimum wages & 172 & $16.35 \%$ \\
\hline More than 6 minimum wages & 280 & $26.62 \%$ \\
\hline I'd rather not answer & 70 & $6.65 \%$ \\
\hline
\end{tabular}

45 years old , and $0.6 \%$ preferred not to answer. Related to marital status, the sample is predominantly single/bachelor $(62.5 \%)$ or in a stable union or married $(33.4 \%)$, while only $3.8 \%$ reported being divorced or widow, and $0.4 \%$ preferred not to answer. As far as education level is concerned, a little more than half $(50.5 \%)$ participants were with a postgraduate degree (MBA and Ph.D.), 28.7\% with complete graduation, $20.4 \%$ completed elementary or high school, and $0.4 \%$ preferred not to answer.

\section{PLS analysis (partial least squares)}

This section presents the analysis of partial least squares (partial least squares) through two stages: evaluation of the model of measurement and analysis of the structural model, both presented in the sequence.

\section{Model evaluation—validity and reliability}

From the export of the primary data collected for the SmartPLS software, the report of the preliminary data obtained 
was generated. The evaluation of the model was initiated through its convergent validity (via average variance extracted-AVE), discriminant validity (via cross-loadings, HTMT, and Fornell-Larcker criterion), and reliability of the model/Internal consistency reliability (via composite reliability), as recommended by Hair Jr et al. (2017).

AVEs for the latent variables are greater than zero, indicating a convergence validity of 0.50 , acceptable according to Hair Jr et al. (2012) and Ringle et al. (2014). Only the $\mathrm{C} / \mathrm{L}$ AVE dimension $<0.5(0.339)$ and, according to Ringle et al. (2014), in these situations, observed variables of the dimensions presenting $<0.50$ should be eliminated. Thus, the two items that showed factor loadings of lower values were eliminated (COV1 and COV2). Later, the data were recalculated, reaching values higher than 0.5 in all the AVE, according to Table 4.

After ensuring convergent validity, the next step consisted of evaluating the discriminant validity of the model, which indicates whether constructs or variables are independent of each other (Hair Jr et al. 2017). According to Ringle et al. (2014) and Hair Jr et al. (2012), the convergent validity can be ascertained through the Fornell-Lacker criterion, in which the square roots of the AVE must be greater than the correlations between the constructs (Fornell and Larcker 1981) and by observing cross-loadings, where each indicator must be higher in the construct intended to measure (Chin 1998). We evaluate, first, the criterion of Fornell-Larcker, which, according to Hair Jr et al. (2017), is considered more conservative. Table 4 presents the values of the correlations between dimensions and square roots of the AVE values on the main diagonal (boldunderline).

In Table 4, the values of the correlations are higher than the square roots of their AVE; therefore, the Fornell-Larcker criterion was confirmed. Subsequently, cross-loading scans were analyzed according to Chin's (1998) criterion, which proved to be adequate, as set out in Table 5:

Analyzing Table 5, it is verified that the factor loadings of the observed variables are higher when compared to the

Table 4 Fornell-Larcker criterion, composite reliability, and AVE

\begin{tabular}{llllll}
\hline & COV & EOU & OP & PI & PU \\
\hline COV & $\underline{\mathbf{0 . 7 0 9}}$ & & & & \\
EOU & 0.123 & $\underline{\mathbf{0 . 7 8 0}}$ & & & \\
OP & 0.119 & 0.404 & $\underline{\mathbf{0 . 7 2 2}}$ & & \\
PI & 0.159 & 0.629 & 0.648 & $\underline{\mathbf{0 . 7 8 7}}$ & \\
PU & 0.209 & 0.709 & 0.454 & 0.656 & $\underline{\mathbf{0 . 7 9 4}}$ \\
$\begin{array}{l}\text { Composite } \\
\text { reliability }\end{array}$ & $\mathbf{0 . 7 7 9}$ & $\mathbf{0 . 8 8 5}$ & $\mathbf{0 . 8 0 9}$ & $\mathbf{0 . 8 6 6}$ & $\mathbf{0 . 8 9 4}$ \\
AVE & $\mathbf{0 . 5 0 3}$ & $\mathbf{0 . 6 0 8}$ & $\mathbf{0 . 5 2 2}$ & $\mathbf{0 . 6 1 9}$ & $\mathbf{0 . 6 3 1}$ \\
\hline
\end{tabular}

Bold: significant correlation between dimensions; Boldunderline: square roots of AVE values
Table 5 Cross loading values

\begin{tabular}{llllll}
\hline Item & COV & EOU & OP & PI & PU \\
\hline COV3 & $\mathbf{0 . 2 3 1}$ & -0.013 & 0.001 & 0.011 & 0.059 \\
COV4 & $\mathbf{0 . 8 7 3}$ & 0.116 & 0.133 & 0.155 & 0.194 \\
COV5 & $\mathbf{0 . 8 3 4}$ & 0.113 & 0.097 & 0.151 & 0.181 \\
COV6 & $\mathbf{0 . 7 0 7}$ & 0.061 & 0.037 & 0.055 & 0.110 \\
EOU1 & 0.057 & $\mathbf{0 . 8 0 7}$ & 0.302 & 0.486 & 0.523 \\
EOU2 & 0.135 & $\mathbf{0 . 8 3 6}$ & 0.406 & 0.591 & 0.739 \\
EOU3 & 0.133 & $\mathbf{0 . 7 6 0}$ & 0.329 & 0.495 & 0.553 \\
EOU4 & 0.045 & $\mathbf{0 . 6 6 3}$ & 0.192 & 0.340 & 0.372 \\
EOU5 & 0.082 & $\mathbf{0 . 8 2 2}$ & 0.296 & 0.485 & 0.488 \\
OP1 & 0.135 & 0.484 & $\mathbf{0 . 8 8 1}$ & 0.710 & 0.503 \\
OP2 & 0.069 & 0.247 & $\mathbf{0 . 7 8 1}$ & 0.416 & 0.266 \\
OP3 & 0.061 & 0.180 & $\mathbf{0 . 5 8 9}$ & 0.281 & 0.253 \\
OP4 & 0.036 & 0.066 & $\mathbf{0 . 5 9 7}$ & 0.262 & 0.146 \\
PI1 & 0.146 & 0.578 & 0.448 & $\mathbf{0 . 7 9 8}$ & 0.597 \\
PI2 & 0.105 & 0.318 & 0.507 & $\mathbf{0 . 6 8 3}$ & 0.342 \\
PI3 & 0.139 & 0.530 & 0.463 & $\mathbf{0 . 8 1 4}$ & 0.586 \\
PI4 & 0.111 & 0.524 & 0.622 & $\mathbf{0 . 8 4 3}$ & 0.515 \\
PU1 & 0.184 & 0.416 & 0.267 & 0.390 & $\mathbf{0 . 6 7 9}$ \\
PU2 & 0.175 & 0.540 & 0.332 & 0.491 & $\mathbf{0 . 7 7 3}$ \\
PU3 & 0.127 & 0.613 & 0.288 & 0.437 & $\mathbf{0 . 7 7 0}$ \\
PU4 & 0.199 & 0.592 & 0.439 & 0.629 & $\mathbf{0 . 8 7 0}$ \\
PU5 & 0.153 & 0.630 & 0.441 & 0.617 & $\mathbf{0 . 8 6 2}$ \\
\hline RU & & &
\end{tabular}

Bold: Crossed factor loadings of the observed variables

other constructs. The correlations' heterotrait-monotrait ratio (HTMT) also measured the discriminant validity. The HTMT is the mean value of the item correlations across constructs relative to the mean of the average correlations for the items measuring the same construct (Hair Jr et al. 2019). HTMT is expected to be lower than 0.85 (for conceptually different constructs) or lower than 0.90 (for conceptually similar constructs) (Hair Jr et al. 2019). The Online Appendix shows that HTMT is significantly lower than the threshold value (HTMT <0.85).

Thus, the model has discriminant validity. Finally, the values of internal consistency were evaluated through composite reliability. In Table 4, the composite reliability index was higher than 0.7 (Ringle et al. 2014; Hair Jr et al. $2012,2017)$ for $\operatorname{COV}(0.779)$, EOP $(0.885)$, OP $(0.809)$, PI (0.866), and PU AQ7 (0.894). Also, we tested model fit by using the standardized root mean square residual (SRMR). Henseler et al. (2014) suggest the SRMR as a goodness-of-fit measure for PLS-SEM that can be used to avoid model misspecification. It is expected that SRMR is $<0.08$, which was the case in the data analysis in the present study $(\mathrm{SRMR}=0.079)$.

Therefore, by validating the measurement model based on the criteria described above, the next section will analyze the structural model. 


\section{Structural model assessment}

The first evaluation performed at this stage analyzed collinearity through the variance inflation factor (VIF). According to Hair Jr et al. (2009), non-compliance with this assumption may make inferences based on the model erroneous or unreliable. It is stressed that, in the context of PLS-SEM, when the VIF values are higher, the level of collinearity is higher, and ideally fetched a VIF value of less than three since the value equal to or greater than five indicates a potential problem of collinearity (Hair Jr et al. 2017). Table 6 shows the values of our study:

As values are less than three, we continue with all variables. Subsequently, Pearson's coefficients of determination $\left(R^{2}\right)$ were evaluated. According to Ringle et al. (2014, p. 67), $R^{2}$ "evaluates the variance of endogenous variables, which the structural model explains." According to Cohen
(2013), for social and behavioral sciences, the coefficient usually varies between 2 and $26 \%$, being $R^{2}=0.02$ considered a small effect; $R^{2}=0.13$, average effect; and $R^{2}=0.26$, large effect.

The values observed were perceived usefulness $\left(R^{2}=0.518\right)$, perceived ease of purchase $\left(R^{2}=0.015\right)$, online purchase intentions $\left(R^{2}=0.485\right)$, and online purchase $\left(R^{2}=0.420\right)$. It is verified that the endogenous latent variables result in $R^{2}$ above the percentage suggested as a large effect (Cohen 2013) and high (Hair Jr et al. 2011), except for dimension perceived ease of purchase (1.5\%). The model explained a substantial part of the variation of endogenous variables, specifically $42 \%, 48.5 \%$, and $51.8 \%$ of the variation of online purchase, online purchase intentions, and usefulness. Thus, Fig. 2 presents the study research model and summarizes the observed $R^{2}$.
Table 6 Figures for variance inflation factor (VIF)

\begin{tabular}{llllllll}
\hline Item & VIF & Item & VIF & Item & VIF & Item & VIF \\
\hline COV3 & 1.080 & EOP3 & 1.653 & OP4 & 1.276 & PU2 & 1.729 \\
COV4 & 1.678 & EOP4 & 1.638 & PI1 & 1.697 & PU3 & 1.689 \\
COV5 & 1.467 & EOP5 & 2.269 & PI2 & 1.435 & PU4 & 2.663 \\
COV6 & 1.517 & OP1 & 1.511 & PI3 & 1.875 & PU5 & 2.510 \\
EOU1 & 1.947 & OP2 & 1.533 & PI4 & 1.899 & & \\
EOU2 & 1.926 & OP3 & 1.245 & PU1 & 1.462 & & \\
\hline
\end{tabular}

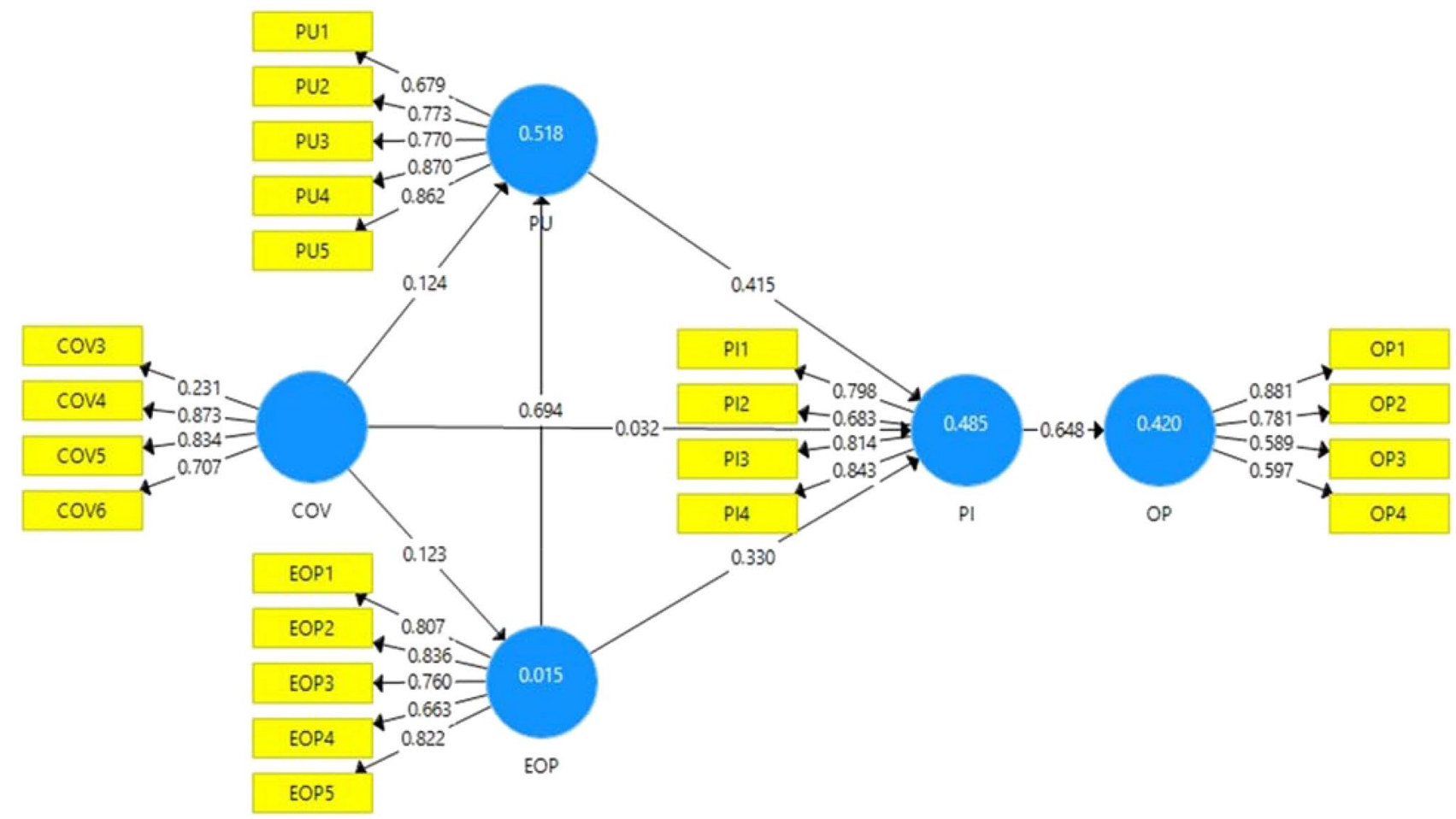

Fig. 2 Study framework and $R^{2}$ 
Subsequently, to test the significance of the relationships mentioned, the bootstrapping technique was used to evaluate the significance ( $\mathrm{p}$ value) of the correlations (measurement models) and the regressions (structural model). Thus, a procedure and analysis of bootstrapping resampling were performed with 5000 samples. Table 7 summarizes the results of the hypothesis tests performed.

As shown in Table 7, the results are above the reference value (1.96), except for Hypothesis 3 ( $T=1.383 ; p$ value $>0.05$ ). In the other cases, $\mathrm{H}_{0}$ was rejected so that the correlations and regression coefficients are significant, providing support for the proposed model. Therefore, six hypotheses were supported with a $p$ value $<0.001$. A figure with the bootstrapping results is available in the Online Appendix.

\section{Discussion of results}

The perceived risk of being infected by COVID-19 when making purchases was positively related to perceived usefulness $(T=5352 ; p<0.001)$ and perceived ease of purchase $(T=3706 ; p<0.001)$, supporting Hypotheses 1 and 2 . These results suggest that as they realize the possible risks related to face-to-face purchases, consumers come to understand that online shopping is safer/more useful and provides them with greater ease/convenience.

However, the perceived risk of being infected by COVID19 when buying in person had no statistically significant influence on online purchase intention $(T=1383 ; p>0.05)$, not supporting Hypotheses 3 . The discovery is based on the evidence observed in previous studies, such as Nguyen et al. (2020) and Yan et al. (2020), who observed the COVID-19 pandemic as an influencer of online purchase intention. The dissonance may be explained in part by the research context where Nguyen et al. (2020) observed the consumption of books and Yan et al. (2020) observed automobiles and possible cultural differences between Brazilian respondents and studies on Asian cultures. This result is also out of previous research that observed the perceived risk as an important determinant of purchase intention (Chiu et al. 2014; Zhang et al. 2018; Yan et al. 2020).

The results of assessing Hypothesis 4 suggest that perceived usefulness is positively related to online purchase intention $(T=10,818 ; p<0.001)$, supporting the hypothesis. Previous studies also found this behavior (e.g., Chiu et al. 2005; Law et al. 2016; Moslehpour et al. 2018; Sukno and Riquelme 2019). Thus, realizing that online purchases will provide greater efficiency than face-to-face purchases, consumers will be more interested in making such purchases.

Empirical evidence also supported Hypothesis 5, related to the positive relationship between perceived ease of purchase and perceived usefulness $(T=36,684 ; p<0.001)$. It is in line with the previous studies that also observed that perceived ease of use positively affected perceived usefulness (Çelik and Yilmaz 2011; Isaac et al. 2017; Arora and Sahney 2018; Moslehpour et al. 2018; Manis and Choi 2019; Sukno and Riquelme 2019). Hypothesis 6 was supported, having seen the significant positive association between perceived ease of purchase and the intention of online purchase ( $T=9,648 ; p<0.001)$, corroborating the findings in the literature (Chiu et al. 2005; Law et al. 2016). The results suggest that by understanding that online shopping will require less effort than a face-to-face purchase, consumers perceive online shopping will improve their buying performance and have greater intention to make purchases in this way.

Finally, there was a significant positive association between intention and purchase intention $(T=36,666$; $p<0.001$ ), supporting Hypothesis 7 . This result is in line with the literature (Çelik and Yilmaz 2011; Wang and Herrando 2019), where consumer purchase intent is positively associated with your actual online purchase. Most respondents claimed to have made more than five purchases in the last three months (during the pandemic), staying more than 15 min per week performing their online shopping. In this way, the acceptance of these hypotheses meets the idea that the more companies can demonstrate to their consumers that online shopping will bring them benefits, such as ease of use and time savings, the greater their purchase intention and, consequently, makes them buy more online. Companies can further exploit such benefits in times of health

\begin{tabular}{llllllll}
\hline Path & Hypothesis & VIF & Original sample & $\begin{array}{l}\text { Standard } \\
\text { deviation }\end{array}$ & T statistics & p value & Results \\
\hline $\mathrm{COV} \rightarrow$ PU & $\mathrm{H} 1(+)$ & 1.015 & 0.124 & 0.023 & 5.352 & 0.000 & Supported \\
$\mathrm{COV} \rightarrow$ EOU & $\mathrm{H} 2(+)$ & 1.000 & 0.123 & 0.033 & 3.706 & 0.000 & Supported \\
$\mathrm{COV} \rightarrow \mathrm{PI}$ & $\mathrm{H} 3(+)$ & 1.047 & 0.032 & 0.023 & 1.383 & 0.167 & Rejected \\
$\mathrm{PU} \rightarrow$ PI & $\mathrm{H} 4(+)$ & 2.076 & 0.415 & 0.038 & 10.818 & 0.000 & Supported \\
$\mathrm{EOU} \rightarrow \mathrm{PU}$ & $\mathrm{H} 5(+)$ & 1.015 & 0.694 & 0.019 & 36.684 & 0.000 & Supported \\
$\mathrm{EOU} \rightarrow$ PI & $\mathrm{H} 6(+)$ & 2.016 & 0.330 & 0.034 & 9.648 & 0.000 & Supported \\
$\mathrm{PI} \rightarrow \mathrm{OP}$ & $\mathrm{H} 7(+)$ & 1.000 & 0.648 & 0.018 & 36.666 & 0.000 & Supported \\
\hline
\end{tabular}


emergencies, showing how buying online will bring fewer risks than a face-to-face purchase (at the company itself or its competitor).

\section{Final considerations}

This study aimed to analyze the influence of COVID-19 on online shopping behavior. The results reveal a significant impact of the perceived risk of being infected by COVID-19 when buying in person to perceived usefulness and ease of online purchase, which, in turn, influence online purchase intention. The intention to purchase online has also positively influenced online shopping. Such findings are essentially in harmony with the previous research.

That said, it can be concluded that the findings of this study indicate that the COVID-19 pandemic influences online shopping behavior, since, at this time, people fear being infected when accessing physical retail environments and find in the online environment the ease of being able to access this purchase without having to leave the comfort of their homes and expose themselves to risk. Furthermore, it is also possible to note that this moment of greater exposure to digital media favors the growth of online shopping because the consumer who has an intention to buy online most likely decides to make such a purchase.

\section{Implications of the study}

The study presents theoretical, managerial, and social contributions. From a theoretical point of view, this article contributes to the body of literature on online purchasing decisions. The findings of the study also contributed to corroborate the results of studies and theoretical propositions of authors such as Chiu et al. (2005), Çelik and Yilmaz (2011), Law et al. (2016), Arora and Sahney (2018), Moslehpour et al. (2018), Zhang et al. (2018), Sukno and Riquelme (2019), and Wang and Herrando (2019).

From the point of view of management contributions, the understanding of consumer buying behavior in the use of the virtual environment to the detriment of face-to-face, especially in this pandemic scenario, to make their purchases, it is crucial for companies and marketing professionals to rethink their strategic actions focusing on better conducting, planning and realignment of their products and services primarily the omnichannel perspective.

The study presents social contributions; from the moment that companies understand the behavior of online buying, they can improve the experience, access, and usability that will be socially useful in the day-to-day of the population and especially in a crisis. The study also contributes to the guidance of authorities and policymakers and economic recovery plans, suggesting that perceived risk when shopping in physical stores influences consumers to make their purchases online.

\section{Research limitations and future research directions}

Like any scientific study, this also presents some methodological limitations. The sample is composed only of Brazilian consumers and, since this is a non-probabilistic sample, inference to the rest of the population is not possible. Therefore, future studies can be conducted in the Brazilian and international context with the proposed model, with a more representative sampling process, and a random selection of respondents.

The proposed model does not consider all possible variables influencing consumers' online purchase behavior. The data collection occurred at the beginning of winter and a few months in the pandemic when there were more mobility restrictions, influencing the decision to buy online. Thus, it is suggested to improve the theoretical model tested here, including other variables and dimensions not considered in the present study or the use of the current model at different moments of the pandemic. It is also recommended to use the model proposed herein studies on online shopping in specific segments, such as food and clothing.

However, although it is recognized that the results and implications of the present study are limited and require caution in its extrapolation and generalization, it is evident that these limitations do not compromise the analyses performed and the contributions presented by the same to academia, the market, and society.

Supplementary Information The online version contains supplementary material available at https://doi.org/10.1057/s41270-022-00156-9.

Funding Funding was provided by $\mathrm{CNPq}$ (Grant Number 437254/2018-6).

\section{References}

Addo, P.C., F. Jiaming, N.B. Kulbo, and L. Liangqiang. 2020. COVID19: Fear appeal favoring purchase behavior towards personal protective equipment. The Service Industries Journal 40 (7-8): $471-490$.

Arora, S., and S. Sahney. 2018. Antecedents to consumers' showrooming behavior: An integrated TAM-TPB framework. Journal of Consumer Marketing.

Brewer, P., and A.G. Sebby. 2021. The effect of online restaurant menus on consumers' purchase intentions during the COVID-19 pandemic. International Journal of Hospitality Management 94: 102777.

Çelik, H.E., and V. Yilmaz. 2011. Extending the technology acceptance model for adoption of e-shopping by consumers in Turkey. Journal of Electronic Commerce Research 12 (2): 152.

Chi, T. 2018. Understanding Chinese consumer adoption of apparel mobile commerce: An extended TAM approach. Journal of Retailing and Consumer Services 44: 274-284. 
Chin, W.W. 1998. The partial least squares approach to structural equation modeling. Modern Methods for Business Research 295 (2): 295-336.

Chiu, Y.B., C.P. Lin, and L.L. Tang. 2005. Gender differs: assessing a model of online purchase intentions in e-tail service. International Journal of Service Industry Management 16(5).

Chiu, C.M., E.T. Wang, Y.H. Fang, and H.Y. Huang. 2014. Understanding customers' repeat purchase intentions in $\mathrm{B} 2 \mathrm{C}$ e-commerce: The roles of utilitarian value, hedonic value, and perceived risk. Information Systems Journal 24 (1): 85-114.

Chu, K.M. 2018. Mediating influences of attitude on internal and external factors influencing consumers' intention to purchase organic foods in China. Sustainability 10 (12): 4690.

Cohen, J. 2013. Statistical power analysis for the behavioral sciences. Cambridge: Academic Press.

Davis, F.D., and V. Venkatesh. 1996. A critical assessment of potential measurement biases in the technology acceptance model: Three experiments. International Journal of Human-Computer Studies 45 (1): 19-45.

Fayad, R., and D. Paper. 2015. The technology acceptance model e-commerce extension: A conceptual framework. Procedia Economics and Finance 26: 1000-1006.

Fedorko, I., R. Bacik, and B. Gavurova. 2018. Technology acceptance model in e-commerce segment. Management \& Marketing 13 (4): $1242-1256$.

Fornell, C., and D.F. Larcker. 1981. Evaluating structural equation models with unobservable variables and measurement error. Journal of Marketing Research 18 (1): 39-50.

Fortes, N., and P. Rita. 2016. Privacy concerns and online purchasing behaviour: Towards an integrated model. European Research on Management and Business Economics 22 (3): 167-176.

Hair, J.F., Jr., G.T.M. Hult, C. Ringle, and M. Sarstedt. 2017. A primer on partial least squares structural equation modeling (PLS-SEM). Los Angeles: Sage Publications.

Hair, J.F., Jr., C.M. Ringle, and M. Sarstedt. 2011. PLS-SEM: Indeed a silver bullet. Journal of Marketing Theory and Practice 19 (2): 139-152.

Hair, J.F., Jr., J.J. Risher, M. Sarstedt, and C.M. Ringle. 2019. When to use and how to report the results of PLS-SEM. European Business Review 31 (1): 2-24.

Hair, J.F., Jr., M. Sarstedt, C.M. Ringle, and J.A. Mena. 2012. An assessment of the use of partial least squares structural equation modeling in marketing research. Journal of the Academy of Marketing Science 40 (3): 414-433.

Henseler, J., et al. 2014. Common beliefs and reality about partial least squares: Comments on Rönkkö and Evermann. Organizational Research Methods 17 (2): 182-209.

Isaac, O., Z. Abdullah, T. Ramayah, and A.M. Mutahar. 2017. Internet usage within government institutions in Yemen: An extended technology acceptance model (TAM) with Internet self-efficacy and performance impact. Science International 29 (4): 737-747.

Ishfaq, N., and H. Mengxing. 2021. Consumer usage behavior of internet-based services (IBS) in Pakistan during COVID-19 crisis from the perspective of technology acceptance model. Environmental Science and Pollution Research 1-16.

Kantar. 2020. COVID-19: Impacts on consumption and brands. Webinar Kantar Brazil. https://br.kantar.com/covid-19

Kemp, S. 2020. Digital around the world in April 2020. We are Social. https://wearesocial.com/blog/2020/04/digit al-around-the-world-in-april-2020

Kietzmann, J.H., K. Hermkens, I.P. McCarthy, and B.S. Silvestre. 2011. Social media? Get serious! Understanding the functional building blocks of social media. Business Horizons 54 (3): 241-251.

Kim, J.B. 2012. An empirical study on consumer first purchase intention in online shopping: Integrating initial trust and TAM. Electronic Commerce Research 12 (2): 125-150.
Kim, R.Y. 2020. The Impact of COVID-19 on consumers: Preparing for digital sales. IEEE Engineering Management Review.

Kim, S.S., J. Kim, F. Badu-Baiden, M. Giroux, and Y. Choi. 2021. Preference for robot service or human service in hotels? Impacts of the COVID-19 pandemic. International Journal of Hospitality Management, 93.

Koufaris, M. 2002. Applying the technology acceptance model and flow theory to online consumer behavior. Information Systems Research 13 (2): 205-223.

Law, M., R.C.W. Kwok, and M. Ng. 2016. An extended online purchase intention model for middle-aged online users. Electronic Commerce Research and Applications 20: 132-146.

Lee, D.Y., and M.R. Lehto. 2013. User acceptance of YouTube for procedural learning: An extension of the Technology Acceptance Model. Computers and Education 61: 193-208.

Manis, K.T., and D. Choi. 2019. The virtual reality hardware acceptance model (VR-HAM): Extending and individuating the technology acceptance model (TAM) for virtual reality hardware. Journal of Business Research 100: 503-513.

Moslehpour, M., V.K. Pham, W.K. Wong, and İ Bilgiçli. 2018. E-purchase intention of Taiwanese consumers: Sustainable mediation of perceived usefulness and perceived ease of use. Sustainability 10 (1): 234.

Nguyen, H.V., H.X. Tran, L. Van Huy, X.N. Nguyen, M.T. Do, and N. Nguyen. 2020. Online book shopping in Vietnam: The impact of the COVID-19 pandemic situation. Publishing Research Quarterly 100: 1-9.

Ringle, C.M., D. Da Silva, and D.D.S. Bido. 2014. Modeling of structural equations using SmartPLS. Revista Brasileira De Marketing 13 (2): 56-73.

Sheth, J. 2020. Impact of Covid-19 on consumer behavior: will the old habits return or die? Journal of Business Research 117: 280-283.

Shim, J., J. Moon, M. Song, and W.S. Lee. 2021. Antecedents of purchase intention at Starbucks in the context of covid-19 pandemic. Sustainability 13 (4): 1758.

Silva, L.E.N., M.B. Gomes Neto, R. da Grangeiro, and R., and Nadae, J. de. 2021. COVID-19 pandemic: Why does it matter for consumer research? Brazilian Journal of Marketing 20 (2): 253-278.

Sukno, R., and I. Pascual del Riquelme. 2019. E-Commerce C2C en Chile: Incorporación de la Reputación y de la Confianza en el TAM. Journal of Technology Management and Innovation 14 (3): $72-81$.

Sun, L. 2017. The timing game of new disruptive technology adoption under competition. In Academy of Management Proceedings, no. 1, p. 13270. New York: Academy of Management.

Tong, X. 2010. A cross-national investigation of an extended technology acceptance model in the online shopping context. International Journal of Retail and Distribution Management 38 (10): 742-759. https://doi.org/10.1108/09590551011076524.

Troise, C., A. O’Driscoll, M. Tani, and A. Prisco. 2021. Online food delivery services and behavioural intention-A test of an integrated TAM and TPB framework. British Food Journal 123 (2): 664-683.

Ventre, I., and Kolbe, D. (2020). The Impact of Perceived Usefulness of Online Reviews, Trust and Perceived Risk on Online Purchase Intention in Emerging Markets: A Mexican Perspective. Journal of International Consumer Marketing, 1-13.

Wang, Y., and C. Herrando. 2019. Does privacy assurance on social commerce sites matter to millennials? International Journal of Information Management 44: 164-177.

Wang, Y., A. Hong, X. Li, and J. Gao. 2020. Marketing innovations during a global crisis: A study of China firms' response to COVID-19. Journal of Business Research 116: 214-220.

Wee, C.S., M.S.B.M. Ariff, N. Zakuan, M.N.M. Tajudin, K. Ismail, and N. Ishak. 2014. Consumers perception, purchase intention 
and actual purchase behavior of organic food products. Review of Integrative Business and Economics Research 3 (2): 378.

Who. 2020. Coronavirus disease (COVID-19) Situation Report-176. https://www.who.int/docs/default-source/coronaviruse/situationreports/20200714-covid-19-sitrep-176.pdf?sfvrsn=d01ce263_2

Yan, Y., S. Zhong, J. Tian, and N. Jia. 2020. An empirical study on consumer automobile purchase intentions influenced by COVID19. SSRN 3593963.

Zhang, X., S. Liu, X. Chen, L. Wang, B. Gao, and Q. Zhu. 2018. Health information privacy concerns, antecedents, and information disclosure intention in online health communities. Information \& Management 55 (4): 482-493.

Publisher's Note Springer Nature remains neutral with regard to jurisdictional claims in published maps and institutional affiliations.

João Coelho Soares is a PhD student at the Federal University of Santa Catarina, Brazil, a researcher in consumer behavior, and a member of the Organizational Competitive Intelligence Center in Marketing and Logistics (Nico/UFSC/CNPq) research group. His recent writings have appeared in the International Journal of Sustainability in Higher Education and Online Information Review.

Ricardo Limongi is a professor of marketing at Federal University of Goiás. His research interests are marketing performance, machine learning and econometric social media models. His recent writing have appeared in the Journal of Marketing Management, Online Information Review and International Journal of Emerging Markets.

João Henriques De Sousa Júnior is a $\mathrm{PhD}$ student at the Federal University of Santa Catarina, Brazil, a researcher in marketing and consumer behavior, and is a member of the Organizational Competitive Intelligence Center in Marketing and Logistics (Nico/UFSC/CNPq) research group.

Weverson Soares Santos is a master's in management in Federal University of Santa Catarina, Brazil, a researcher in marketing and consumer behavior, and is a marketing executive in pharmaceutical industry.

Michele Raasch is a PhD student at the Federal University of Santa Catarina, Brazil, a researcher in marketing, consumer behavior and organizational strategy, and is a member of the Organizational Competitive Intelligence Center in Marketing and Logistics (Nico/UFSC/ $\mathrm{CNPq}$ ) research group.

Lenoir Hoeckesfeld is a Professor at Federal Institute of Mato Grosso (IFMT), PhD in Management at University of Vale do Itajaí, Researcher at Process and Develop of Management Strategies Research Group (PROFORME/UNIVALI), Mato Grosso, Brazil. 